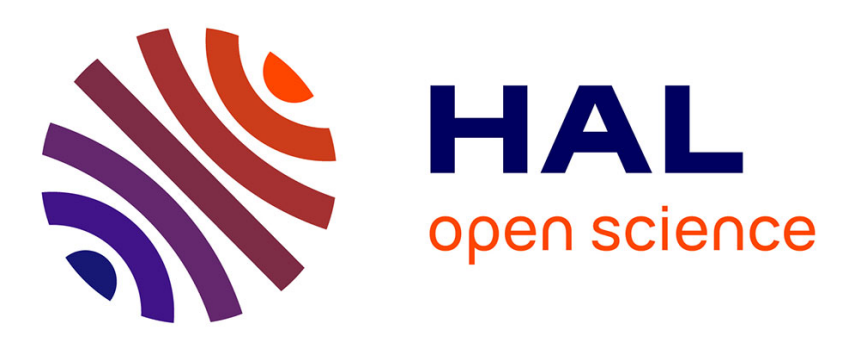

\title{
Flow (shear stress)-mediated remodeling of resistance arteries in diabetes.
}

Emilie Vessières, Mohamed L. Freidja, Laurent Loufrani, Céline Fassot, Daniel Henrion

\section{- To cite this version:}

Emilie Vessières, Mohamed L. Freidja, Laurent Loufrani, Céline Fassot, Daniel Henrion. Flow (shear stress)-mediated remodeling of resistance arteries in diabetes.. Vascular Pharmacology, 2012, 57 (5-6), pp.173-8. 10.1016/j.vph.2012.03.006 . inserm-00768638

\section{HAL Id: inserm-00768638 https://www.hal.inserm.fr/inserm-00768638}

Submitted on 22 Dec 2012

HAL is a multi-disciplinary open access archive for the deposit and dissemination of scientific research documents, whether they are published or not. The documents may come from teaching and research institutions in France or abroad, or from public or private research centers.
L'archive ouverte pluridisciplinaire HAL, est destinée au dépôt et à la diffusion de documents scientifiques de niveau recherche, publiés ou non, émanant des établissements d'enseignement et de recherche français ou étrangers, des laboratoires publics ou privés. 


\title{
Flow (shear stress)-mediated remodeling of resistance arteries in diabetes
}

Emilie Vessières, Lamine M. Freidja, Laurent Loufrani, Céline Fassot, Daniel Henrion.

Dept of Integrated Neurovascular and Mitochondrial Biology

UMR CNRS 6214 - INSERM 1083,

University of Angers,

France

Address for correspondence:

Dr D. Henrion, Pharm.D., Ph.D.,

Dept of Integrated Neurovascular and Mitochondrial Biology

UMR CNRS 6214 - INSERM 1083,

Faculté de Médecine,

49045 Angers

France

Tel: +3241735845

Fax: +32 417358 95/96

E-mail: daniel.henrion@univ-angers.fr

Web site: www.bnmi.fr

\begin{abstract}
Shear stress due to blood flow is the most important force stimulating vascular endothelium. Acute stimulation of the endothelium by shear stress induces a vasodilatation mainly due to the release of nitric oxide (NO) among other relaxing agents. After a chronic increase in blood flow (shear stress), the endothelium triggers diameter enlargement, medial hypertrophy and improvement of arterial contractility and endothelium-mediated dilation. Shear stressmediated outward remodeling requires an initial inflammatory response followed by the production of reactive oxygen species (ROS) and peroxinitrite anions, which activate MMPs and extracellular matrix digestion allowing diameter expansion. This outward remodeling occurs in collateral growth following occlusion of a large artery. In diabetes, an excessive ROS production is associated with the formation of advanced glycation end-products (AGEs) and the glycation of enzymes involved in vascular tone. The balance between inflammation, AGEs and ROS level determines the ability of resistance arteries to develop outward remodeling whereas AGEs and ROS contribute to decrease endothelium-mediated dilation in remodeled vessels. This review explores the interaction between ROS, AGEs and the endothelium in shear stress-mediated outward remodeling of resistance arteries in diabetes. Restoring or maintaining this remodeling is essential for an efficient blood flow in distal organs.
\end{abstract}

Abbreviations:

EDHF: endothelium-derived hyperpolarizing factor; FMD: flow-mediated dilation; NO: nitric oxide; ROS: reactive oxygen species; ONOO-: peroxinitrite anion; eNOS: endothelial NOsynthase; FMD: flow-mediated dilation; MMPs: metalloproteases; ECM: extracellular matrix; AT1/2R: angiotensin II type 1 or 2 receptor.

Key words: Endothelium, resistance arteries, mechanotransduction, remodeling, shear stress 


\section{A. Introduction}

The endothelium plays a central role in vascular homeostasis and allows the vasculature to adapt to the local need of each tissue. In response to various stimuli, the endothelium produces nitric oxide (NO) from the amino acid L-arginin that induces the relaxation of the muscular layer and vascular dilation. In resistance arteries, the endothelium produces vasodilator agents such as prostacyclin and EDHF as well as vasoconstrictor agents such as angiotensin II, thromboxan $\mathrm{A}_{2}\left(\mathrm{TxA}_{2}\right)$ and endothelin-1. Pulsatile blood flow produces three types of hemodynamic forces: a) hydrostatic pressure generated by the liquid, aa) cyclic stretching and aaa) shear stress. Stretching is a cyclic distension of the wall caused by a transmural pressure gradient and depends on thickness of the vessel wall, its composition and the degree of contraction of smooth muscle. The main effect of cyclic stretching is the induction of oxidative stress in endothelial cells. On the other hand, shear stress results from the frictional forces exerted by blood flow directly on endothelial cells and is determined by blood flow, blood viscosity and vessel diameter. Acute changes in blood flow or shear stress induce immediate changes in tone by activating endothelial cells, which produce vasoactive agents. In response to a chronic change in flow, the endothelium induces deeper changes in arterial wall structure and function usually referred as remodeling.

Diabetes is increasing worldwide in industrialized as well as in developing countries, posing a major challenge to global human health. Cardiovascular diseases are the major cause of morbidity and mortality in type 2 diabetes due to arterial structure and functional alteration. The most important damages observed in diabetic patients are hind limb ischemia and end organ damages [1]. Vascular damages associated with diabetes could be explained in part by the reduction of small resistance arteries capacity to adapt in response to chronic changes in blood flow. Indeed, shear stress-mediated remodeling of small resistance arteries is essential for collateral growth following arterial occlusion and for revascularization of ischemic tissues, a key problem in diabetes.

This article focuses on the role of the endothelium in flow-mediated remodeling of resistance arteries and on the changes induced by metabolic syndrome and diabetes. Indeed, local blood flow supply is a critical issue in metabolic disorders associated with overweight and/or diabetes.

\section{B. Control of microvascular tone and role of shear stress}

The vasculature consists of large arteries branching out into smaller and smaller vessels terminated by capillaries. Capillaries irrigate tissues and are connected to larger veins via venules. Structural and functional differences between large arteries and arterioles are obvious when comparing the aorta to pre-capillary arterioles. Indeed, differences in blood pressure, pulsatility, and organ or tissue specificity induce a specialization of vascular cells. Changes in the hemodynamic environment induce short-term responses and structural adaptation of the vascular tree, thus allowing an optimal tissue perfusion [2,3]. Small arteries having the most important influence on local blood flow are called resistance arteries. These arteries are submitted to chemical and neuro-hormonal influences in addition to the continuous effect of the mechanical factors generated by the blood stream, mainly pressure and flow. Pressure induces a rapid and sustained vasoconstriction called myogenic tone [4-6]. Myogenic tone represents a tonic arteriolar contraction facilitating the action of the other vasoactive systems, mainly the sympathetic and the renin-angiotensin systems, through a 
synergistic mechanism or potentiation, controlling the sensitivity to calcium of the contractile apparatus [7-12]. This potentiation relies mainly on the activation of the RhoA-Rho-kinase pathway [13] leading to a higher level of filamentous actin in the cytosol [14]. On the other hand, blood flow produces shear stress, which stimulates the endoluminal surface of the endothelium. Flow (shear stress)-mediated dilation (FMD) represents a basal vasodilator stimulus activating continuously the endothelium. Together with myogenic tone, FMD determines a basal tone over which other vasoactive systems may act more efficiently. Shear stress induces the production of nitric oxide (NO), prostacyclin and endothelium-derived hyperpolarizing factor (EDHF) as well as the production of vasoconstrictor agents such as endothelin-1 and angiotensin II [15]. A reduction in FMD is the hallmark of endothelial dysfunction and it is becoming more and more important in the detection, the follow-up and even the prevention of vascular disorders in a growing number of diseases described in recent review articles [16-18]. As shown in a recent review article [19], a change in flow (shear stress) induces a complex response of the endothelial cell with the involvement of the extracellular matrix, the primary cilia and membrane-associated proteins, mainly ionic channels and adhesion molecules. The signal may also be transmitted to surrounding cells through the cytoskeleton and the integrins. Each may be affected by diabetes, especially in response to chronic changes in flow. Acute responses to flow seems to be rather affected by the excessive oxidative stress occurring in diabetes leading to reduced NO bioavailability.

To assess the endothelial dysfunction in patients, a flow-mediated dilation method can be carried out noninvasively with ultrasonography on the brachial artery [20]. Thus, it has been demonstrated not only an alteration in FMD [21,22] but also carotid intima-media thickness and arterial stiffness increases even before the onset of type 2 diabetes [23]. Interestingly, the reduction in FMD is inversely related to the extent of hyperglycemia [22]. Nevertheless, the underlying patho-physiological mechanisms remain to be fully elucidated. A complete understanding of the association between arterial alterations is critical for the primary prevention of diabetes-associated vascular disorders. Diabetes increases substantially the risk of developing ischemic cardiovascular events. Consequently, in diabetic individuals, there is a high incidence of critical limb ischemia and lower extremity amputation. It is most likely that impaired compensatory responses in the setting of acute or chronic ischemia in diabetes are responsible for this poor clinical outcome. Besides a reduced vasodilatation, diabetes is also associated with a decreased revascularization as evidenced in experimental models [24,25]. Post-ischemic revascularization involves several mechanisms. Following occlusion of a large artery, arterial blood flow is redirected through adjacent preexisting collateral smaller arteries. In addition, hypoxia induces angiogenesis in the ischemic area. Thus, the consequent increase in shear stress induces outward remodeling of the preexisting collateral arteries [26]. As vasodilatation is the initial step leading to outward remodeling, the impairment in FMD observed in diabetes is most likely associated with impaired remodeling leading to decreased revascularization. As described below, flow-mediated outward remodeling is inefficient in diabetes and this defect may be in part responsible for the hypertrophic remodeling this disease. Indeed, in both type 1 and type 2 diabetes, the arterial wall is hypertrophic, at least in large blood vessels. Hypertrophic remodeling of subcutaneous small arteries is also present in non-insulino-dependent diabetes as evidenced by an increase in tunica media to internal lumen ratio. This remodeling is equivalent to that observed in hypertension and associated with reduced FMD [27]. This remodeling in small resistance arteries in diabetes might be due to a higher inflammatory state linked to oxidative stress [28].

\section{C- Mechanotransduction of flow (shear stress): chronic responses}

\section{1- Microcirculatory adaptation to chronic changes in blood flow}


Chronic increases in blood flow induce arterial wall remodeling allowing tissues and organs to adapt to a new hemodynamic environment. Arterial remodeling is defined as a change in structure and function of the component of the wall, mainly the endothelium and the muscle. In resistance arteries chronic increases in wall shear stress induces a remodeling triggered by endothelial cell and consisting of a diameter enlargement aiming at normalizing shear stress. This is associated with a compensatory hypertrophy normalizing circumferential strain due to dilation and with improvement of endothelium-mediated dilation due, at least in part to increased eNOS expression level [29-32]. This remodeling is involved as a response to an increase in the metabolic need of different tissues during growth, following exercise training or during pregnancy. Flow-mediated remodeling allows a better perfusion of the downstream-located tissues. It is also expected when a collateral growth is needed after ischemia. Substantial evidence shows that this collateral growth is impaired in the presence of risk factors such as aging [31,33,34], metabolic syndrome [32,35], hypertension [36] or diabetes [37].

Remodeling of resistance arteries due to high blood pressure has been widely investigated $[5,38]$. On the other hand, reorganization of the arterial wall after chronic changes in blood flow has been mainly studied in large arteries allowing a better understanding of diseases such as atherosclerosis and aneurysms [39,40]. In the microcirculation, the occurrence of remodeling is not clear and the mechanisms involved not yet fully described. Nevertheless, in ischemic and metabolic diseases, flow-mediated remodeling of resistance arteries has a key role besides angiogenesis and arteriogenesis [41,42]. After chronic exercise training, which increases chronically blood flow, resistance arteries diameter increases in association with an enhanced endothelial capacity to produce NO and prostanoids [43]. Similarly, chronic vasodilator treatments increase local blood flow with consequences on wall structure and function similar to those due to exercise training [44]. In order to investigate selectively changes in wall structure and function occurring in response to blood flow variations, a model has been developed in the mesenteric vascular bed. In short, arteries are alternatively ligated so that they are submitted to low, high or normal blood flow without changes in blood pressure, hormonal environment or body mass $[45,46]$. In this model, chronic increases and decreases in blood flow induce outward and inward arterial remodeling, respectively. Arterial wall remodeling is accompanied by a compensatory change in medial mass, which restores circumferential wall stress [46,47]. A chronic increase in blood flow also increases the dilatory capacity of the endothelium, especially in response to shear stress or vasodilator agonists [29,32,48-50]. Endothelial cells from high-flow arteries express more eNOS than control arteries $[30,32,51]$ and the production of NO is critical for the diameter enlargement [30]. Indeed, NO acts in association with reactive oxygen species (ROS) to form peroxinitrites $\left(\mathrm{ONOO}^{-}\right)$, which in turn activate MMPs; as shown in the carotid artery [52] and in the mesenteric circulation [53].

Arterial wall hypertrophy associated with the increase in diameter involves the local production of angiotensin II as either angiotensin I converting enzyme inhibition or angiotensin II type 1 receptor blockade prevented the hypertrophy without affecting the increase in diameter [54]. This is in agreement with previous works showing the involvement of the local renin-angiotensin system in the vascular response to shear stress $[15,55,56]$. Intriguingly, ROS production and ERK1/2 are involved in both outward remodeling due to high flow and in inward remodeling due to low flow. Indeed, the inflammatory response is the central link between the two type of response as previously demonstrated by Bakker et al. [57] who have shown that the inflammatory response triggers the remodeling process but the 
type of response (outward or inward) is directed by vascular tone. Finally the last step also relies on a common mechanism. Indeed, when outward or inward remodeling is established, associated to a normalization of shear stress, tissue-transglutaminases stabilize the arterial wall $[58,59]$. Among the nine members of the transglutaminase family, three are expressed in the vasculature: type 1, type 2 and factor XIII. Cross-linking of proteins is the main feature of transglutaminases providing mechanical strength to tissues. Their involvement in other processes in vascular biology is more recent. Their role in endothelial barrier function or small artery remodeling is summarized in a recent review article [60].

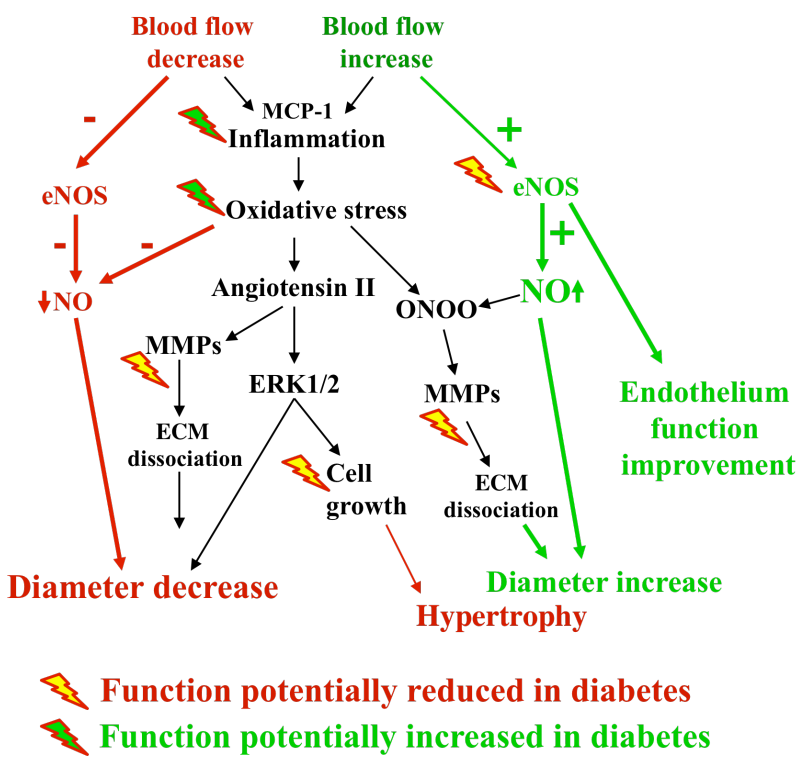

Figure 1: Changes in blood flow, decreases or increases, induce an inflammatory response responsible for oxidative stress and synthesis of angiotensin II. This results in activation of metalloproteases (MMPS) that cause a partial dissociation of the extracellular matrix (ECM). The next step depends on the basal stimulus inducing the remodeling. In arteries subjected to increased flow, the endothelium is over-stimulated and produced more NO, which increases arterial diameter. In arteries subjected to low flow, the endothelium is under-stimulated and produces less NO. Thus NO counteracts less angiotensin II that can then contract the artery. In all cases, the remodeling is stabilized when the diameter reaches a level allowing normalization of shear stress. In the artery submitted to high-flow, activation of angiotensin II type 1 receptor and MAP kinase ERK1/2 induces a compensatory hypertrophy.

\section{2 - High blood flow-mediated-remodeling in pathological conditions}

\subsection{Vascular ageing and oxidative stress}

High flow-mediated remodeling is impaired in physiological aging in the rat [31,33]. Nevertheless, increasing blood flow in two-year old rats remains able to induce hypertrophy [31] and to improve endothelium-mediated dilation [61]. A recent study has also shown that an antioxidant treatment with either tempol or apocynin reverses age-related collateral growth impairment, suggesting that an excessive oxidative stress opposes diameter enlargement [62]. As both hydralazine and the antioxidant drugs tested are potentially vasodilator, it remains possible that the threshold for flow sensing is shifted in aging toward larger shear stress values and that any drug increasing shear stress will be efficient. This hypothesis remains to be demonstrated. An excessive oxidative stress might oppose remodeling in pathological 
situations. Nevertheless, induction of endothelial cell tube formation in vitro and coronary collateral growth in vivo requires a specific intracellular concentration of ROS. ROS levels below and above this optimal range prohibit coronary collateral development and endothelial cell tube formation [63]. This is in agreement with our previous observation demonstrating the essential role of ROS in flow-mediated arterial enlargement [53] and with another study showing that ROS inhibit the same remodeling in young spontaneously hypertensive (SHR) rats [64] as well as in old normotensive rats [65].

\subsection{Obesity without diabetes or with moderate diabetes}

In the Zucker rat, a model of metabolic syndrome with obesity associated with moderate diabetes and hypertension, flow-mediated diameter enlargement occurs without improvement of endothelium-mediated dilation. Indeed, in high-flow vessels, FMD is worsened compared to control arteries associated with a reduced implication of NO [32]. This is in agreement with previous studies showing in Zucker obese rats, an endothelial dysfunction in several vascular beds [66] associated with a reduced NO concentration [67] and an increase of vascular oxidative stress [66], which is associated with eNOS uncoupling [68]. Thus, even if the "structural" remodeling occurred after a chronic increase in blood flow, endotheliumdependent dilation was not improved but further deteriorated. This could support elevated vascular resistance, moderate hypertension or limited oxygenation of host organs. In addition, the endothelial alteration following chronic rise in blood flow might have negative consequences in the long-term when patients suffering metabolic syndrome are recommended to practice exercise or are given vasodilator treatments. Of course, these studies were performed in rat mesenteric arteries and this conclusion may not entirely apply to other vascular territories, as exercising, in controlled conditions, has been proven efficient in obese patients. Indeed, regular and moderate training has pleiotropic effects and consequently does not only affect the vasculature [69].

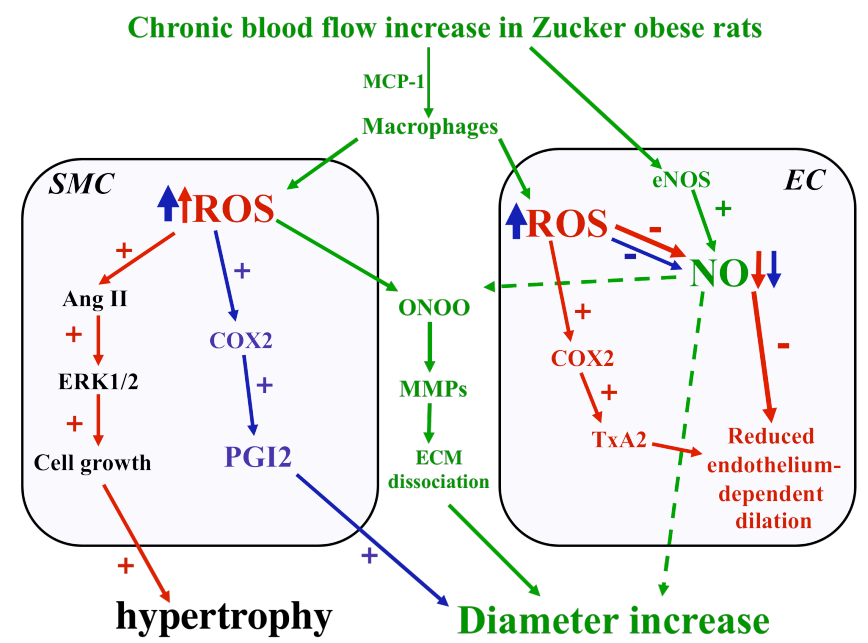

Figure 2: High flow-mediated remodeling in a rat model of metabolic syndrome. A chronic increase in blood flow induces inflammation and oxidative stress. This latter added to pre-existing oxidative stress due to obesity and moderate diabetes induces an exaggerated hypertrophy of the arterial wall and an additional deterioration of endothelial-dependent dilation, however activation of metalloproteases (MMPs) by peroxinitrites (ONOO) persists and causes a partial dissociation of the extracellular matrix (ECM). Green arrows refer to physiological remodeling and red arrows point out the effect of metabolic syndrome on the process.

In old Zucker rats (in blue), oxidative stress is higher than in young rats. As a consequence, endothelium-mediated dilation is more severely impaired. Despite important reduction in NO 
availability, the production of prostacyclin (PGI2 produced by COX2) induces vasodilatation sufficient to increase arterial diameter.

$E C=$ endothelial cell; $S M C=$ smooth muscle cell.

Paradoxically, high flow-mediated remodeling remains fully efficient in one-year old obese Zucker rats, by contrast with control rats in which remodeling is impaired as described above. Nevertheless, even though diameter enlargement occurred, endothelium-dependent dilation was strongly impaired in association with a larger oxidative stress than in other arteries from Zucker rats [70]. Indeed, the moderate increase in oxidative stress associated with a chronic rise in blood flow occurs above a pre-existing oxidative stress and consequently, NOmediated dilation is further decreased. Although NO production is strongly reduced in old Zucker rats, remodeling occurred, due to a COX2-dependent production of vasodilator prostanoids, possibly prostacyclin. Indeed, the pharmacological treatment of rats with celecoxib, a COX2 blocker, inhibited diameter enlargement [70]. COX2 is expressed in old Zucker rats mesenteric arteries together with an excessive oxidative stress [50]. This maintenance of a larger arterial diameter in old Zucker was not observed in other vascular territories where arterial narrowing usually occurs [71]. Interestingly, mesenteric blood flow is higher in obese Zucker rats than in lean animals [72,73]. Thus local inflammation in obesity might preserve high mesenteric blood flow, which may participates to the development of obesity.

\subsection{Flow-mediated remodeling of resistance arteries and diabetes}

On the opposite, we found in young Zucker diabetic fatty (ZDF) rats that flow-mediated arterial enlargement is impaired [74]. Nevertheless, in diabetic animal, remodeling may also be impaired due to excessive advanced glycation end products (AGEs) accumulation [75]. The flow-sensing process is probably not sufficiently impaired to explain this observation as in response to the chronic increase in flow both eNOS and caveolin-1 expression were enhanced similarly to control lean rats. This observation rules out, at least in part, a possible reduction in flow sensing by advanced glycation end products (AGEs), which have been shown to reduce the activity of several processes in type 2 diabetes. AGEs have been reported to alter the matrix proteins collagen, vitronectin, and laminin, through AGE-AGE intermolecular covalent bonds, or cross-linking [76,77]. The absence of remodeling is probably not the consequence of the overweight observed in ZDF rats as in obese Zucker nondiabetic rats outward remodeling occurred normally [32]. Thus, it is most likely that extracellular matrix digestion is affected by AGEs and that this defect prevents remodeling. This assumption is supported by a study showing that, in diabetes, revascularization following femoral artery ligation is reduced by AGE formation. Indeed, the authors have shown that AGEs reduce extracellular-matrix degradation by MMPs and subsequently abrogates the angiogenic process needed for revascularization [24]. This study has also shown that abrogating AGEs formation with aminoguanidin restored angiogenesis in diabetic (type 1, induced by streptozotocin) rats. In diabetic rabbits (type 1, induced by alloxan), growth of collateral arteries was estimated by the measurement of arterial size using X-ray radiography [25]. This work suggests that reduced collateral arterial growth observed in diabetes is associated with a decreased monocyte chemotaxis and growth factor signaling. So far, it seems that the presence of AGEs is the main determinant of the altered remodeling found in diabetes, more than the type of diabetes, type 1 or type 2 . Nevertheless, no study has yet really compared the two types of diabetes using a similar model. 
In isolated arteries of ZDF rats, abnormally high oxidative stress dramatically reduces endothelium (NO)-mediated dilation in arteries submitted to high blood flow mainly because of NO scavenging and eNOS uncoupling [68]. In ZDF rats, besides NO scavenging by reactive oxygen species, thromboxan $\mathrm{A}_{2}$ generated by COX-2 also reduces endotheliummediated dilation [53].

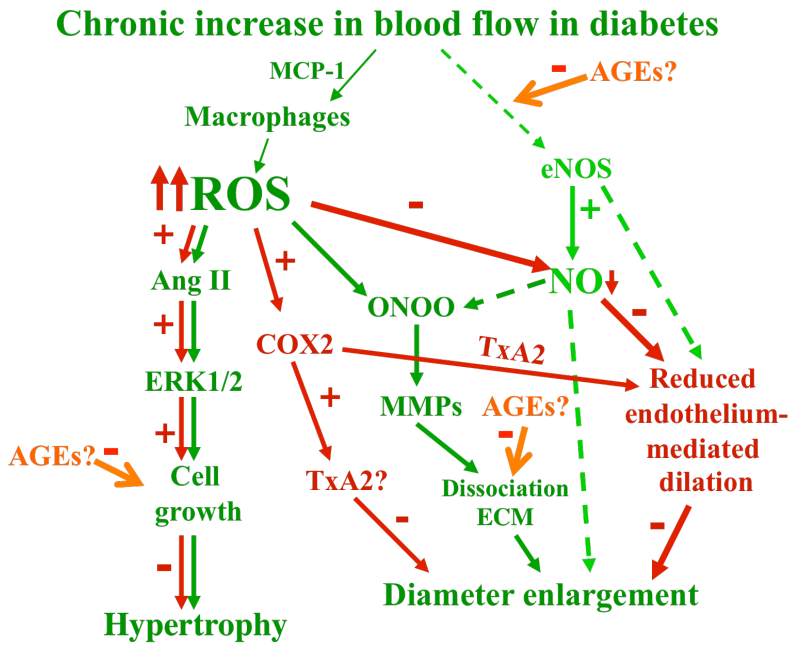

Figure 3: High flow-mediated remodeling in a rat model of type 2 diabetes. A chronic increase in blood flow induces inflammation and oxidative stress. This latter added to pre-existing oxidative stress due to obesity and moderate diabetes induces an exaggerated hypertrophy of the arterial wall and an additional deterioration of endothelial-dependent dilation. In addition, activation of metalloproteases $(M M P S)$ by peroxinitrites (ONOO) might be prevented by AGEs and consequently extracellular matrix (ECM) would not occur, thus preventing diameter expansion. Green arrows refer to physiological remodeling and red arrows point out the effect of diabetes on the process. Alternatively, cyclooxigenase-2 (COX-2) derived thromboxan $A_{2}\left(T x A_{2}\right)$ might also reduced diameter enlargement and endothelium-mediated dilation.

\section{Conclusion}

Shear stress-mediated remodeling is essential for collateral growth following arterial occlusion and for revascularization of ischemic tissues. It depends on the equilibrium between the production of NO and of that of superoxide anions. In diseases such as diabetes and obesity, an excessive ROS production disrupts this equilibrium and thus the capacity of resistance arteries to adapt to chronic increases in blood flow. In diabetes, AGEs increase the dysfunction and, added to ROS prevents remodeling and reduces endothelium-mediated dilation. Fighting both AGEs formation and oxidative stress represents a reasonable way to reduce vascular damages associated with diabetes especially in distant organs.

\section{References:}

[1] Schaper NC, Nabuurs-Franssen MH, Huijberts MS. Peripheral vascular disease and type 2 diabetes mellitus. Diabetes Metab Res Rev 2000;16 Suppl 1:S11-15.

[2] Bevan JA, Siegel G. Blood vessel wall matrix flow sensor: Evidence and speculation. Blood Vessels 1991;28:552-556.

[3] Bevan JA, Henrion D. Pharmacological implications of the flow-dependence of vascular smooth muscle tone. Annu Rev Pharmacol Toxicol 1994;34:173-190.

[4] Henrion D. Pressure and flow-dependent tone in resistance arteries. Role of myogenic tone. Arch Mal Coeur Vaiss 2005;98:913-921. 
[5] Prewitt RL, Rice DC, Dobrian AD. Adaptation of resistance arteries to increases in pressure. Microcirculation 2002;9:295-304.

[6] Hill MA, Davis MJ, Meininger GA, Potocnik SJ, Murphy TV. Arteriolar myogenic signalling mechanisms: Implications for local vascular function. Clin Hemorheol Microcirc 2006;34:67-79.

[7] Henrion D, Laher I, Laporte R, Bevan JA. Further evidence from an elastic artery that angiotensin ii amplifies noradrenaline-induced contraction through activation of protein kinase c. Eur J Pharmacol 1992;224:13-20.

[8] Henrion D, Laher I, Laporte R, Bevan JA. Angiotensin ii amplifies arterial contractile response to norepinephrine without increasing ca++ influx: Role of protein kinase c. $\mathrm{J}$ Pharmacol Exp Ther 1992;261:835-840.

[9] Dowell FJ, Henrion D, Duriez M, Michel JB. Vascular reactivity in mesenteric resistance arteries following chronic nitric oxide synthase inhibition in wistar rats. $\mathrm{Br} \mathrm{J}$ Pharmacol 1996;117:341-346.

[10] Dowell FJ, Henrion D, Benessiano J, Poitevin P, Levy B. Chronic infusion of lowdose angiotensin ii potentiates the adrenergic response in vivo. J Hypertens 1996;14:177-182.

[11] Iglarz M, Matrougui K, Levy BI, Henrion D. Chronic blockade of endothelin eta receptors improves flow dependent dilation in resistance arteries of hypertensive rats. Cardiovasc Res 1998;39:657-664.

[12] Yeon DS, Kim JS, Ahn DS, Kwon SC, Kang BS, Morgan KG, Lee YH. Role of protein kinase c- or rhoa-induced $\mathrm{ca}(2+)$ sensitization in stretch-induced myogenic tone. Cardiovasc Res 2002;53:431-438.

[13] Dubroca C, Loyer X, Retailleau K, Loirand G, Pacaud P, Feron O, Balligand JL, Levy BI, Heymes C, Henrion D. Rhoa activation and interaction with caveolin-1 are critical for pressure-induced myogenic tone in rat mesenteric resistance arteries. Cardiovasc Res 2007;73:190-197.

[14] Cipolla MJ, Gokina NI, Osol G. Pressure-induced actin polymerization in vascular smooth muscle as a mechanism underlying myogenic behavior. Faseb J 2002; 16:72-76.

[15] Matrougui K, Levy BI, Henrion D. Tissue angiotensin ii and endothelin-1 modulate differently the response to flow in mesenteric resistance arteries of normotensive and spontaneously hypertensive rats. Br J Pharmacol 2000;130:521-526.

[16] Feletou M, Vanhoutte PM. Endothelial dysfunction: A multifaceted disorder (the wiggers award lecture). Am J Physiol Heart Circ Physiol 2006;291:H985-1002.

[17] Aird WC. Phenotypic heterogeneity of the endothelium: Ii. Representative vascular beds. Circ Res 2007;100:174-190.

[18] Aird WC. Phenotypic heterogeneity of the endothelium: I. Structure, function, and mechanisms. Circ Res 2007;100:158-173.

[19] Yamamoto K, Ando J. New molecular mechanisms for cardiovascular disease:Blood flow sensing mechanism in vascular endothelial cells. J Pharmacol Sci 2011;116:323-331.

[20] Korkmaz H, Onalan O. Evaluation of endothelial dysfunction: Flow-mediated dilation. Endothelium 2008;15:157-163.

[21] Abdu TA, Elhadd T, Pfeifer M, Clayton RN. Endothelial dysfunction in endocrine disease. Trends Endocrinol Metab 2001;12:257-265.

[22] Christen AI, Armentano RL, Miranda A, Graf S, Santana DB, Zocalo Y, Baglivo HP, Sanchez RA. Arterial wall structure and dynamics in type 2 diabetes mellitus methodological aspects and pathophysiological findings. Curr Diabetes Rev 2010;6:367-377.

[23] Djaberi R, Beishuizen ED, Pereira AM, Rabelink TJ, Smit JW, Tamsma JT, Huisman MV, Jukema JW. Non-invasive cardiac imaging techniques and vascular tools for the assessment of cardiovascular disease in type 2 diabetes mellitus. Diabetologia 2008;51:15811593. 
[24] Tamarat R, Silvestre JS, Huijberts M, Benessiano J, Ebrahimian TG, Duriez M, Wautier MP, Wautier JL, Levy BI. Blockade of advanced glycation end-product formation restores ischemia-induced angiogenesis in diabetic mice. Proc Natl Acad Sci U S A 2003; 100:8555-8560.

[25] van Golde JM, Ruiter MS, Schaper NC, Voo S, Waltenberger J, Backes WH, Post MJ, Huijberts MS. Impaired collateral recruitment and outward remodeling in experimental diabetes. Diabetes 2008;57:2818-2823.

[26] Buschmann I, Schaper W. Arteriogenesis versus angiogenesis: Two mechanisms of vessel growth. News Physiol Sci 1999;14:121-125.

[27] Rizzoni D, Rosei EA. Small artery remodeling in diabetes mellitus. Nutr Metab Cardiovasc Dis 2009; 19:587-592.

[28] Rosei EA, Rizzoni D. Small artery remodelling in diabetes. J Cell Mol Med 2010;14:1030-1036.

[29] Pourageaud F, De Mey JG. Vasomotor responses in chronically hyperperfused and hypoperfused rat mesenteric arteries. Am J Physiol 1998;274:H1301-1307.

[30] Dumont O, Loufrani L, Henrion D. Key role of the no-pathway and matrix metalloprotease-9 in high blood flow-induced remodeling of rat resistance arteries. Arterioscler Thromb Vasc Biol 2007;27:317-324.

[31] Dumont O, Pinaud F, Guihot AL, Baufreton C, Loufrani L, Henrion D. Alteration in flow (shear stress)-induced remodelling in rat resistance arteries with aging: Improvement by a treatment with hydralazine. Cardiovasc Res 2008;77:600-608.

[32] Bouvet C, de Chantemele EB, Guihot AL, Vessieres E, Bocquet A, Dumont O, Jardel A, Loufrani L, Moreau P, Henrion D. Flow-induced remodeling in resistance arteries from obese zucker rats is associated with endothelial dysfunction. Hypertension 2007;50:248-254.

[33] Tuttle JL, Hahn TL, Sanders BM, Witzmann FA, Miller SJ, Dalsing MC, Unthank JL. Impaired collateral development in mature rats. Am J Physiol Heart Circ Physiol 2002;283:H146-155.

[34] Nakae I, Fujita M, Miwa K, Hasegawa K, Kihara Y, Nohara R, Miyamoto S, Ueda K, Tamaki S, Sasayama S. Age-dependent impairment of coronary collateral development in humans. Heart Vessels 2000;15:176-180.

[35] Turhan H, Yasar AS, Erbay AR, Yetkin E, Sasmaz H, Sabah I. Impaired coronary collateral vessel development in patients with metabolic syndrome. Coron Artery Dis 2005;16:281-285.

[36] Tuttle JL, Sanders BM, Burkhart HM, Fath SW, Kerr KA, Watson WC, Herring BP, Dalsing MC, Unthank JL. Impaired collateral artery development in spontaneously hypertensive rats. Microcirculation 2002;9:343-351.

[37] Belin de Chantemele EJ, Vessieres E, Guihot AL, Toutain B, Maquignau M, Loufrani L, Henrion D. Type 2 diabetes severely impairs structural and functional adaptation of rat resistance arteries to chronic changes in blood flow. Cardiovasc Res 2009;81:788-796.

[38] Mulvany MJ. Small artery remodeling in hypertension. Curr Hypertens Rep 2002;4:49-55.

[39] Langille BL. Arterial remodeling: Relation to hemodynamics. Can J Physiol Pharmacol 1996;74:834-841.

[40] Lehoux S, Castier Y, Tedgui A. Molecular mechanisms of the vascular responses to haemodynamic forces. J Intern Med 2006;259:381-392.

[41] Silvestre JS, Mallat Z, Tedgui A, Levy BI. Post-ischaemic neovascularization and inflammation. Cardiovasc Res 2008;78:242-249.

[42] Carmeliet P. Mechanisms of angiogenesis and arteriogenesis. Nat Med 2000;6:389395. 
[43] Koller A, Huang A, Sun D, Kaley G. Exercise training augments flow-dependent dilation in rat skeletal muscle arterioles. Role of endothelial nitric oxide and prostaglandins. Circ Res 1995;76:544-550.

[44] Gorny D, Loufrani L, Kubis N, Levy BI, Henrion D. Chronic hydralazine improves flow (shear stress)-induced endothelium-dependent dilation in mouse mesenteric resistance arteries in vitro. Microvasc Res 2002;64:127-134.

[45] Unthank JL, Fath SW, Burkhart HM, Miller SC, Dalsing MC. Wall remodeling during luminal expansion of mesenteric arterial collaterals in the rat. Circ Res 1996;79:1015-1023.

[46] Pourageaud F, De Mey JG. Structural properties of rat mesenteric small arteries after 4-wk exposure to elevated or reduced blood flow. Am J Physiol 1997;273:H1699-1706.

[47] Buus CL, Pourageaud F, Fazzi GE, Janssen G, Mulvany MJ, De Mey JG. Smooth muscle cell changes during flow-related remodeling of rat mesenteric resistance arteries. Circ Res 2001;89:180-186.

[48] Loufrani L, Li Z, Levy BI, Paulin D, Henrion D. Excessive microvascular adaptation to changes in blood flow in mice lacking gene encoding for desmin. Arterioscler Thromb Vasc Biol 2002;22:1579-1584.

[49] Freidja ML, Vessieres E, Clere N, Desquiret V, Guihot AL, Toutain B, Loufrani L, Jardel A, Procaccio V, Faure S, Henrion D. Heme oxygenase-1 induction restores high-bloodflow-dependent remodeling and endothelial function in mesenteric arteries of old rats. $\mathrm{J}$ Hypertens 2011;29:102-112.

[50] Freidja ML, Toutain B, Caillon A, Desquiret V, Lambert D, Loufrani L, Procaccio V, Henrion D. Heme oxygenase 1 is differentially involved in blood flow-dependent arterial remodeling: Role of inflammation, oxidative stress, and nitric oxide. Hypertension 2011;58:225-231.

[51] Tulis DA, Unthank JL, Prewitt RL. Flow-induced arterial remodeling in rat mesenteric vasculature. Am J Physiol 1998;274:H874-882.

[52] Castier Y, Brandes RP, Leseche G, Tedgui A, Lehoux S. P47phox-dependent nadph oxidase regulates flow-induced vascular remodeling. Circ Res 2005;97:533-540.

[53] Retailleau K, Belin de Chantemele EJ, Chanoine S, Guihot AL, Vessieres E, Toutain B, Faure S, Bagi Z, Loufrani L, Henrion D. Reactive oxygen species and cyclooxygenase 2derived thromboxane a2 reduce angiotensin ii type 2 receptor vasorelaxation in diabetic rat resistance arteries. Hypertension 2010;55:339-344.

[54] Cousin M, Custaud MA, Baron-Menguy C, Toutain B, Dumont O, Guihot AL, Vessieres E, Subra JF, Henrion D, Loufrani L. Role of angiotensin ii in the remodeling induced by a chronic increase in flow in rat mesenteric resistance arteries. Hypertension 2010;55:109-115.

[55] Henrion D, Benessiano J, Levy BI. In vitro modulation of a resistance artery diameter by the tissue renin-angiotensin system of a large donor artery. Circ Res 1997;80:189-195.

[56] Matrougui K, Loufrani L, Heymes C, Levy BI, Henrion D. Activation of at(2) receptors by endogenous angiotensin ii is involved in flow-induced dilation in rat resistance arteries. Hypertension 1999;34:659-665.

[57] Bakker EN, Matlung HL, Bonta P, de Vries CJ, van Rooijen N, Vanbavel E. Blood flow-dependent arterial remodelling is facilitated by inflammation but directed by vascular tone. Cardiovasc Res 2008;78:341-348.

[58] Bakker EN, Pistea A, Spaan JA, Rolf T, de Vries CJ, van Rooijen N, Candi E, VanBavel E. Flow-dependent remodeling of small arteries in mice deficient for tissue-type transglutaminase: Possible compensation by macrophage-derived factor xiii. Circ Res 2006;99:86-92. 
[59] Bakker EN, Buus CL, Spaan JA, Perree J, Ganga A, Rolf TM, Sorop O, Bramsen LH, Mulvany MJ, Vanbavel E. Small artery remodeling depends on tissue-type transglutaminase. Circ Res 2005;96:119-126.

[60] Matlung HL, Bakker EN, VanBavel E. Shear stress, reactive oxygen species, and arterial structure and function. Antioxid Redox Signal 2009;11:1699-1709.

[61] Yan C, Huang A, Kaley G, Sun D. Chronic high blood flow potentiates shear stressinduced release of no in arteries of aged rats. Am J Physiol Heart Circ Physiol 2007;293:H3105-3110.

[62] Miller SJ, Coppinger BJ, Zhou X, Unthank JL. Antioxidants reverse age-related collateral growth impairment. J Vasc Res 2010;47:108-114.

[63] Rocic P, Kolz C, Reed R, Potter B, Chilian WM. Optimal reactive oxygen species concentration and p38 map kinase are required for coronary collateral growth. Am J Physiol Heart Circ Physiol 2007;292:H2729-2736.

[64] Zhou X, Bohlen HG, Miller SJ, Unthank JL. Nad(p)h oxidase-derived peroxide mediates elevated basal and impaired flow-induced no production in shr mesenteric arteries in vivo. Am J Physiol Heart Circ Physiol 2008;295:H1008-H1016.

[65] Zhou X, Bohlen HG, Unthank JL, Miller SJ. Abnormal nitric oxide production in aged rat mesenteric arteries is mediated by nad(p)h oxidase-derived peroxide. Am J Physiol Heart Circ Physiol 2009;297:H2227-2233.

[66] Zanchi A, Delacretaz E, Taleb V, Gaillard R, Jeanrenaud B, Brunner HR, Waeber B. Endothelial function of the mesenteric arteriole and mechanical behaviour of the carotid artery in rats with insulin resistance and hypercholesterolaemia. J Hypertens 1995;13:14631470 .

[67] Bohlen HG. Protein kinase betaii in zucker obese rats compromises oxygen and flowmediated regulation of nitric oxide formation. Am $J$ Physiol Heart Circ Physiol 2004;286:H492-497.

[68] Gao L, Mann GE. Vascular nad(p)h oxidase activation in diabetes: A double-edged sword in redox signalling. Cardiovasc Res 2009;82:9-20.

[69] Teixeira-Lemos E, Nunes S, Teixeira F, Reis F. Regular physical exercise training assists in preventing type 2 diabetes development: Focus on its antioxidant and antiinflammatory properties. Cardiovasc Diabetol 2011;10:12.

[70] Belin de Chantemele EJ, Vessieres E, Guihot AL, Toutain B, Loufrani L, Henrion D. Cyclooxygenase-2 preserves flow-mediated remodelling in old obese zucker rat mesenteric arteries. Cardiovasc Res 2010;86:516-525.

[71] Traupe T, Lang M, Goettsch W, Munter K, Morawietz H, Vetter W, Barton M. Obesity increases prostanoid-mediated vasoconstriction and vascular thromboxane receptor gene expression. J Hypertens 2002;20:2239-2245.

[72] Enevoldsen LH, Stallknecht B, Fluckey JD, Galbo H. Effect of exercise training on in vivo insulin-stimulated glucose uptake in intra-abdominal adipose tissue in rats. Am J Physiol Endocrinol Metab 2000;278:E25-34.

[73] Romanko OP, Stepp DW. Reduced constrictor reactivity balances impaired vasodilation in the mesenteric circulation of the obese zucker rat. Am J Physiol Heart Circ Physiol 2005;289:H2097-2102.

[74] Belin de Chantemele EJ, Vessieres E, Dumont O, Guihot AL, Toutain B, Loufrani L, Henrion D. Reactive oxygen species are necessary for high flow (shear stress)-induced diameter enlargement of rat resistance arteries. Microcirculation 2009;16:391-402.

[75] Freidja ML, Tarhouni K, Toutain B, Fassot-Lucht C, Loufrani L, Henrion D. The agebreaker alt-711 restores high blood flow-dependent remodeling in mesenteric resistance arteries in a rat model of type 2 diabetes. Diabetes 2012 
[76] Rumble JR, Cooper ME, Soulis T, Cox A, Wu L, Youssef S, Jasik M, Jerums G, Gilbert RE. Vascular hypertrophy in experimental diabetes. Role of advanced glycation end products. J Clin Invest 1997;99:1016-1027.

[77] Goldin A, Beckman JA, Schmidt AM, Creager MA. Advanced glycation end products: Sparking the development of diabetic vascular injury. Circulation 2006;114:597-605. 